\title{
Análise de correlação entre as regiões administrativas de Natal (RN) baseada em indicadores de vulnerabilidade socioambiental
}

Este artigo tem como objetivo analisar as correlações lineares existentes entre as regiões administrativas de Natal (RN) com base nos índices de vulnerabilidade socioambiental de seus bairros. $\mathrm{O}$ alcance do objetivo permitirá identificar quais regiões administrativas são mais vulneráveis sob a perspectiva do conjunto de indicadores, além de identificar as similaridades e diferenças existentes entre elas. Em termos metodológicos este artigo se caracteriza como exploratório e descritivo, realizado por meio das técnicas de pesquisa documental para levantar dados e informações necessárias da cidade, bem como os dados referentes aos indicadores de vulnerabilidade socioambiental escolhidos para a análise dos bairros e regiões de Natal. Os resultados apontam que a região Norte foi a região que apresentou um nível de vulnerabilidade classificado como 'Alto'. Essa também é a região mais pobre de Natal e, por conseguinte, a que apresenta os problemas mais latentes nas questões referentes aos temas analisados, sobretudo, Saúde, Trabalho e renda, Infraestrutura Urbana, Educação e cultura. Tal fato o coloca em um nível de correlação linear fraca e de disparidade frente as regiões mais abastadas da cidade: região Leste e região Sul.

Palavras-chave: Vulnerabilidade Socioambiental; Indicadores; Correlação Linear.

\section{Correlation analysis between the administrative regions of Natal (RN) based on socioenvironmental vulnerability indicators}

\begin{abstract}
This article aims to analyze the existing linear correlations between the administrative regions of Natal (RN) based on the socioenvironmental vulnerability indexes of its neighborhoods. The scope of the objective will allow identifying which administrative regions are most vulnerable from the perspective of the set of indicators, in addition to identifying the similarities and differences between them. In methodological terms, this article is characterized as exploratory and descriptive, carried out by documentary research techniques to collect data and necessary information of the city, as well as the data referring to the indicators of social and environmental vulnerability chosen for the analysis of the neighborhoods and regions of Natal. The results indicate that the North region was the region that presented a level of vulnerability classified as 'High'. This is also the poorest region of Natal and, therefore, the one that presents the most latent problems in the issues related to the topics analyzed, especially Health, Work and Income, Urban Infrastructure, Education and Culture. This fact places it in a level of weak linear correlation and of disparity against the richest regions of the city: East and South regions.
\end{abstract}

Keywords: Socio-Environmental Vulnerability; Indicators; Linear Correlation.

Topic: Planejamento Urbano

Reviewed anonymously in the process of blind peer.
Received: 09/02/2020

Approved: 09/03/2020
Ana Cecilia Feitosa de Vasconcelos (iD)

Universidade Federal de Campina Grande, Brasil

http://lattes.cnpq.br/6492366302935662

http://orcid.org/0000-0002-7848-4602

acvasconcelos@gmail.com

Paulo Ribeiro Lins Junior (iD

Instituto Federal da Paraíba, Brasil

http://lattes.cnpq.br/2720405345746056

http://orcid.org/0000-0002-6452-9363

paulo.ribeiro.lins.jr@gmail.com

Eliza Maria Xavier Freire (DD

Universidade Federal do Rio Grande do Norte, Brasil

http://lattes.cnpq.br/6388455734228621

http://orcid.org/0000-0001-9486-6347

elizajuju1000@gmail.com

\author{
Gesinaldo Ataíde Cândido (iD \\ Universidade Federal de Campina Grande, Brasil \\ http://lattes.cnpq.br/2771934125977891 \\ http://orcid.org/0000-0002-3112-0254 \\ gacandido@uol.com.br
}

Referencing this:

VASCONCELOS, A. C. F.; LINS JUNIOR, P. R.; FREIRE, E. M. X.; CÂNDIDO, G. A.. Análise de correlação entre as regiões administrativas de Natal (RN) baseada em indicadores de vulnerabilidade socioambiental. Revista Ibero Americana de Ciências Ambientais, v.11, n.2, p.445461, 2020. DOI: http://doi.org/10.6008/CBPC2179$\underline{6858.2020 .002 .0040}$ 


\section{INTRODUÇÃO}

A discussão acerca da vulnerabilidade passou a despertar o interesse de pesquisadores e instituições de pesquisa, em decorrência dos crescentes índices de desigualdades sociais, da segregação socioespacial e do processo de urbanização desordenado das cidades. Nesta perspectiva, Kowarick (2000) expõe que não só a relação natureza e sociedade gera a vulnerabilidade, mas afirma que existe muita vulnerabilidade em relação a direitos básicos, na medida em que não só os sistemas públicos de proteção social foram sempre restritos e precários, como também, em anos recentes, houve desmonte de serviços e novas regulamentações que se traduziram em perda de direitos adquiridos.

Embasada nesse entendimento é que se reconhece que o estudo da vulnerabilidade envolve uma discussão ampla e relevante por ter um caráter multidisciplinar e indica que a suscetibilidade das pessoas a problemas e danos estão, principalmente, relacionadas ao conjunto das profundas transformações sociais, econômicas e ambientais que afetam, pelo mundo inteiro, as pessoas ou grupos de pessoas (KOWARICK, 2009).

Nesse sentido, um conceito viável para analisar estas relações é o de 'vulnerabilidade socioambiental', que pode ser definida como a coexistência, cumulatividade ou sobreposição espacial de situações de pobreza/privação social e de situações de exposição a risco e/ou degradação ambiental. Assim, é justamente a combinação dessas duas dimensões - social e ambiental - que está sendo considerada uma situação de vulnerabilidade socioambiental (ALVES, 2006).

Nesta perspectiva, a contribuição nos estudos de vulnerabilidade e pobreza tem focado os aspectos estruturais e subjetivos das famílias, levando em consideração o contexto em que estão inseridas: pobreza, exclusão/inclusão, periferização, segregação, dependência e elevado risco (HOGAN et al., 2005). É fato que o fenômeno da vulnerabilidade socioambiental no contexto urbano envolve também as questões sociais de uma população que vai ficando cada vez mais à margem das decisões e encaminhamentos do planejamento urbano. Assim, os indicadores de vulnerabilidade socioambiental tornam-se uma ferramenta fundamental para seu monitoramento e direcionamento de ações.

Nesse contexto, este estudo tem como objetivo analisar as correlações lineares existentes entre as regiões administrativas de Natal (RN) com base nos índices de vulnerabilidade socioambiental de seus bairros. $\mathrm{O}$ alcance do objetivo permitirá identificar quais regiões administrativas são mais vulneráveis sob a perspectiva do conjunto de indicadores, além de identificar as similaridades e diferenças existentes entre elas.

A escolha da cidade deve-se à sua diversidade ambiental e das características sociais da sua população. A capital do Rio Grande do Norte tem sido alvo de muitos investimentos, sobretudo em torno das atividades turísticas e do setor imobiliário, tanto no âmbito público quanto no privado, ao passo que se percebe outras áreas que, em decorrência do crescimento desordenado, exigem uma maior demanda por serviços de infraestrutura e moradia.

Em termos metodológicos este artigo se caracteriza como exploratório e descritivo, por meio das 
técnicas de pesquisa documental para levantar dados e informações necessárias da cidade, bem como os dados referentes aos indicadores de vulnerabilidade socioambiental escolhidos para a análise dos bairros e regiões de Natal. Este artigo, além desta parte introdutória, apresenta os aspectos metodológicos para a concretização do objetivo proposto, os resultados obtidos e as considerações finais.

\section{REVISÃO TEÓRICA}

\section{Indicadores de Vulnerabilidade Socioambiental}

A utilização dos indicadores tem sido basilar na formulação de políticas públicas, pois possibilitam uma análise atual, conhecendo verdadeiramente a situação que se almeja modificar, como também o monitoramento temporal, permitindo um melhor acompanhamento das variáveis analisadas, uma melhor avaliação dos processos e planejamento de ações e, por conseguinte melhor utilização dos recursos investidos.

Vale destacar que a função dos indicadores é o de mensurar uma realidade complexa e que é constituída por uma variedade de partes que se complementam e estão em constante relação de interdependência. Nessa perspectiva, torna-se preponderante identificar as interligações existentes entre os diversos aspectos relacionados ao conceito do fenômeno que se está estudando, aqui de forma específica, a vulnerabilidade socioambiental, para se obter soluções também interligadas para os problemas existentes e potenciais.

Desse modo, qualquer indicador, quer seja ele descritivo ou normativo, se apresenta com uma significância própria. Ou seja, quando comparado com as outras formas de informação dentro do contexto que se está sendo estudado, que definirá a sua importância no direcionamento do planejamento e de ações. Assim, não basta ser apenas significativo para os tomadores de decisão, é preciso antes de tudo, que revele a realidade da sociedade, devendo ser, portanto, importante para o público em geral.

Um bom indicador é aquele que é capaz de revelar uma realidade, simplificando as informações relevantes, comunicando-as e esclarecendo suas facetas. Para Van Bellen (2002), os indicadores são de fato um modelo da realidade, mas não podem ser considerados como a própria realidade, entretanto devem ser analiticamente legítimos e construídos dentro de uma metodologia coerente de mensuração. Para a análise de problemas complexos como é o caso da vulnerabilidade socioambiental, se deve pensar na utilização de indicadores que possam estar interligados e que agreguem várias informações que possam retratar o mais próximo possível uma realidade.

Para tanto, alguns estudos desenvolvidos no contexto urbano enfatizam as problemáticas que acometem as cidades. Dentre eles, destacam-se os autores: Herculano (2000), Sposati (2000), Braga et al. (2002), Nahas (2002), Rossetto (2003), Braga (2006), Alves (2006), Morato (2008), Figueiredo (2008), Ribeiro (2008), Roggero (2009), Florissi (2009), Kowarick (2009), Souza (2009), Machado (2010), Veiga (2010), Jacobs (2011), Pessoa (2012), Araújo et al. (2014), Maior (2014), Maricato (2014), Gehl (2015), Rogers (2015), Rolnik (2015), Roggero (2015), Martins et al. (2015), Pereira et al. (2016), Gomes et al. (2017). 
Após a análise dos estudos desenvolvidos por esses autores, constatou-se que as variáveis apresentadas circundam em torno de alguns aspectos que se repetem. Desse modo, foi possível listar uma série de variáveis que são imprescindíveis ao estudo da vulnerabilidade socioambiental nas cidades, sobretudo, as cidades brasileiras, uma vez que a maioria dos estudos empíricos objetivaram a análise destas como cenário. Desse modo, com base em tais autores compilou-se no Quadro 01, o conjunto de 08 temas e 134 indicadores capazes de analisar a vulnerabilidade socioambiental de cidades brasileiras.

Quadro 1: Indicadores de Vulnerabilidade Socioambiental para cidades brasileiras.

\begin{tabular}{|c|c|c|}
\hline Dimensão & Temas & Indicadores \\
\hline \multirow{5}{*}{ Social } & Saúde & $\begin{array}{l}\text { Oferta de serviços básicos de saúde; Profissionais de Saúde; Taxa de estabelecimento de saúde; Taxa de } \\
\text { estabelecimentos de saúde; Taxa de leitos hospitalares/SUS por } 1000 \text { habitantes; Unidades de média complexidade; } \\
\text { Taxa de unidades de atenção básica; Atendimento odontológicos do SUS; Imunização contra doenças infecciosas } \\
\text { infantis; Taxa de mortalidade infantil; Esperança de vida ao nascer; Taxa de fertilidade; Quant. de adolescentes } \\
\text { grávidas; Quant. de abortos; Quant. de casos de dengue; Quant. de casos de zika; Quant. de casos de chikungunya. }\end{array}$ \\
\hline & $\begin{array}{l}\text { Educação e } \\
\text { Cultura }\end{array}$ & $\begin{array}{l}\text { Taxa de Alfabetização; Taxa de Escolarização; Taxa de escolarização líquida no Ensino Médio; Taxa de escolarização } \\
\text { líquida no Ensino Fundamental; Proporção de jovens de } 15 \text { a } 17 \text { anos sem ensino fundamental completo; Quant. de } \\
\text { escolas de ensino fundamental e médio na proximidade; Quantitativo de matrículas escolares; Pessoas consideradas } \\
\text { potencialmente ativa (15-59 anos) que não sabem ler e escrever; População em idade escolar; Percentual de } \\
\text { professores secundários; Taxa de distorção idade-série; Acesso a computador em casa; Acesso público à internet; } \\
\text { Quant. de museu na proximidade; Quant. de biblioteca na proximidade; Quant. de teatro na proximidade; Número } \\
\text { de estádios e ginásios poliesportivos (ou equipamentos desportivos). }\end{array}$ \\
\hline & $\begin{array}{l}\text { Trabalho e } \\
\text { renda }\end{array}$ & $\begin{array}{l}\text { Índice de Gini; Razão rendimento masculino/feminino; Rendimento mensal domiciliar per capita urbano; } \\
\text { Rendimento familiar per capita (\% até } 1 / 2 \mathrm{SM} \text { ); } \% \text { de famílias com rendimento de } 10 \text { a } 20 \mathrm{SM} \text {; } \% \text { de responsáveis por } \\
\text { domicílio particular permanente com rendimento mensal de até } 2 \mathrm{SM} \text {; } \% \text { de famílias chefiadas por pessoas jovens; } \% \\
\text { de famílias chefiadas por pessoas idosas; População (urbana) com rendimento mensal domiciliar per capita nominal } \\
\text { de até } 1 / 4 \text { salário mínimo; Famílias atendidas por transferências de benefícios sociais; \% de mulheres jovens } \\
\text { responsáveis pelo domicílio; \% de mulheres idosas responsáveis pelo domicílio; Quant. de famílias monoparentais } \\
\text { com chefia feminina ('mães solteiras'); Quant. de pessoas ocupadas nas empresas do setor informal; Taxa de } \\
\text { Ocupação; Taxa de desemprego; Taxa de Formalidade da Ocupação; Quantitativo de indústrias na cidade; } \\
\text { Quantitativo de empresas com incentivos fiscais; População urbana em extrema pobreza. }\end{array}$ \\
\hline & Moradia & $\begin{array}{l}\text { Adequação de moradia; Quant. de pessoas que moram em casa própria; Quant. de assentamentos subnormais na } \\
\text { cidade; População em aglomerados subnormais; Taxa de casas localizadas próximas à córregos e/ou em ambientes } \\
\text { sujeitos à inundação; Taxa de casas localizadas em áreas de acentuada declividade; Domicílio com banheiro - } \\
\text { esgotamento sanitário - rede geral; Percentual de domicílios servidos por rede de esgotamento sanitário; Acesso a } \\
\text { esgotamento sanitário; \% de domicílios particulares permanentes inadequados; \% de domicílios particulares } \\
\text { permanentes sem banheiro; \% de domicílios particulares permanentes com dois ou mais banheiros; Densidade } \\
\text { média de moradores por dormitório; Acesso ao sistema de abastecimento de água; Percentual de domicílios servidos } \\
\text { por rede de água; Domicílios com abastecimento de água - Rede geral, com banheiro; Acesso a serviço de coleta de } \\
\text { lixo doméstico; Percentual de domicílios servidos com algum tipo de coleta de lixo; Densidade média de moradores } \\
\text { de rua; Domicílios com acesso a rede elétrica; População atendida com frequência de } 2 \text { ou } 3 \text { vezes por semana pelo } \\
\text { serviço de coleta de resíduos; Quant. de conjunto habitacional de interesse social }\end{array}$ \\
\hline & Segurança & $\begin{array}{l}\text { Acesso à justiça; Prevenção de delinquência juvenil; Quant. de assaltos; Pessoas (adultos e adolescentes) } \\
\text { dependentes químicos (álcool, drogas); Taxa de violência nas escolas públicas; Quantitativo de empresas ou } \\
\text { profissionais de segurança privada; Profissionais de segurança pública por mil habitantes; Taxa de vítimas de } \\
\text { acidentes de trânsito; Taxa de mortalidade por homicídios. }\end{array}$ \\
\hline \multirow{3}{*}{ Ambiental } & $\begin{array}{l}\text { Infraestrutur } \\
\text { a Urbana }\end{array}$ & $\begin{array}{l}\text { Taxa de urbanização; Taxa de crescimento da população; Densidade demográfica urbana; Quant. de espaço público } \\
\text { para caminhada; Quantitativo de espaços públicos de permanência; Quant. de praças e/ou parques; Equipamentos } \\
\text { públicos; Quant. de ciclovias; Sistema Integrado de Transporte Coletivo; Média de ônibus por linhas; Abrangência do } \\
\text { sistema de transporte coletivo; Qualidade da Frota de ônibus; Quant. de automóveis; Quant. de Acidentes no } \\
\text { trânsito. }\end{array}$ \\
\hline & Governança & $\begin{array}{l}\text { Conselho Municipal de segurança pública; Conselho Municipal do Patrimônio Cultural; Conselho Municipal de } \\
\text { Transporte; Legislação urbanística e ambiental; Legislação municipal de preservação do patrimônio histórico e } \\
\text { cultural; Normas para construção e edificações; Normas para urbanização e regulamentação fundiária; Plano Diretor } \\
\text { participativo; Despesas com melhoria e ampliação do sistema de transporte; Despesas com direito à cidadania; } \\
\text { Despesas com patrimônio cultural e difusão da cultura; Despesas com gestão ambiental; Despesas com Saneamento } \\
\text { Básico Urbano; Despesas com Habitação Urbana; Despesas com Infraestrutura Urbana; Despesas com planejamento } \\
\text { e orçamento; Secretaria municipal de planejamento urbano; Órgãos de defesa do consumidor. }\end{array}$ \\
\hline & $\begin{array}{l}\text { Meio } \\
\text { Ambiente }\end{array}$ & $\begin{array}{l}\text { Consumo médio de energia elétrica urbana; lluminação pública; Empresas de produção de energias alternativas; } \\
\text { Consumo per capita de água(m3/hab); Aferição do cloro residual na água; Amostras de cloro residual dentro do } \\
\text { padrão de qualidade; Aferição de turbidez na água; Amostras de turbidez dentro do padrão de qualidade; Aferição } \\
\text { de coliformes totais na água; Amostras de coliformes totais dentro do padrão de qualidade; Esgoto tratado em } \\
\text { relação ao coletado; Destino do lixo; Coleta seletiva do lixo (IBGE); Resíduos sólidos urbanos per capita; Serviços de } \\
\text { limpeza urbana; Áreas de proteção ambiental; Quant. de árvores per capita }\end{array}$ \\
\hline
\end{tabular}


situação ideal, devendo-se ser atribuído valor 1,00 (nível de vulnerabilidade muito baixo). A ausência dos indicadores na cidade é considerada uma situação irregular, devendo-se ser atribuído valor 0,00 (nível de vulnerabilidade muito alto).

Os temas e indicadores que apresentados no Quadro 1, proporcionará a análise do fenômeno da vulnerabilidade socioambiental, de forma complexa e envolvendo variáveis que abrangem vários aspectos das cidades brasileiras. Desse modo, o tópico seguinte explicitará os aspectos metodológicos utilizados para o alcance do objetivo proposto.

\section{METODOLOGIA}

Este estudo se caracteriza como exploratório e descritivo, dada a necessidade de estabelecer uma hierarquia entre os bairros e regiões de Natal, bem como analisar suas correlações lineares existentes entre os bairros de Natal (RN) através do índice de vulnerabilidade socioambiental de cada bairro. As técnicas de pesquisa adotadas foram a pesquisa documental para levantar dados e informações necessárias da cidade, bem como os dados referentes aos indicadores de vulnerabilidade socioambiental escolhidos para a análise dos bairros de Natal. Dos 134 indicadores apresentados na fundamentação teórica, escolheu-se 72 (Quadro 2) para análise da vulnerabilidade socioambiental da cidade de Natal. A escolha dos indicadores foi realizada em função da disponibilidade dos dados disponíveis no nível de granularidade por bairros.

Quadro 2: Indicadores para análise dos bairros da cidade Natal-RN.

\begin{tabular}{|c|c|c|}
\hline Dimensão & Temas & Indicadores \\
\hline \multirow[t]{4}{*}{ Social } & Saúde & $\begin{array}{l}\text { Profissionais de Saúde por } 1000 \text { Hab.; Taxa de estabelecimentos de saúde; Taxa de unidades de atenção básica; } \\
\text { Taxa de mortalidade infantil; Esperança de vida ao nascer; Taxa de Fertilidade; Quantidade de casos de dengue. }\end{array}$ \\
\hline & $\begin{array}{l}\text { Educação e } \\
\text { Cultura }\end{array}$ & $\begin{array}{l}\text { Taxa de Alfabetização; Taxa de Escolarização; Taxa de escolarização líquida no Ensino Médio; Taxa de } \\
\text { escolarização líquida no Ensino Fundamental; Proporção de jovens de } 15 \text { a } 17 \text { anos sem ensino fundamental } \\
\text { completo; Quantidade de escolas de ensino fundamental e médio na proximidade; Quantitativo de matrículas } \\
\text { escolares; Pessoas consideradas potencialmente ativa (15-59 anos) que não sabem ler e escrever; População em } \\
\text { idade escolar; Taxa de distorção idade-série; Quantidade de museu na proximidade; Quantidade de biblioteca na } \\
\text { proximidade; Quantidade de teatro na proximidade; Número de estádios e ginásios poliesportivos (ou } \\
\text { equipamentos desportivos) }\end{array}$ \\
\hline & $\begin{array}{l}\text { Trabalho e } \\
\text { renda }\end{array}$ & $\begin{array}{l}\text { Índice de Gini; Rendimento mensal domiciliar per capita urbano; Rendimento familiar per capita (\% até } 1 / 2 \text { SM); } \\
\% \text { de famílias com rendimento de } 10 \text { a } 20 \text { SM; População (urbana) com rendimento mensal domiciliar per capita } \\
\text { nominal de até } 1 / 4 \text { salário mínimo; Quantidade de pessoas ocupadas nas empresas do setor informal; Taxa de } \\
\text { Ocupação; Taxa de Desemprego; Taxa de Formalidade da Ocupação; População urbana em extrema pobreza. }\end{array}$ \\
\hline & Moradia & $\begin{array}{l}\text { População em Casa Própria; Quantidade de assentamentos subnormais; População em aglomerados subnormais; } \\
\text { Domicílio com banheiro; Percentual de domicílios servidos por rede de esgotamento sanitário; Densidade média } \\
\text { de moradores por dormitório; Acesso ao sistema de abastecimento de água; Percentual de domicílios servidos } \\
\text { por rede de água; Domicílios com abastecimento de água; Acesso a serviço de coleta de lixo doméstico; Domicílios } \\
\text { com acesso a rede elétrica; População atendida com frequência de } 2 \text { ou } 3 \text { vezes por semana pelo serviço de coleta } \\
\text { de resíduos; Quantidade de conjunto habitacional de interesse social. }\end{array}$ \\
\hline \multirow[t]{2}{*}{ Ambiental } & $\begin{array}{l}\text { Infraestrutur } \\
\text { a Urbana }\end{array}$ & $\begin{array}{l}\text { Taxa de crescimento da população; Densidade demográfica urbana; Quantitativo de praças e/ou parques; } \\
\text { Equipamentos Públicos; Sistema Integrado de Transporte Coletivo; Quantidade de Acidentes no trânsito. }\end{array}$ \\
\hline & $\begin{array}{l}\text { Meio } \\
\text { Ambiente }\end{array}$ & $\begin{array}{l}\text { Consumo per capita de água; Resíduos sólidos urbanos per capita; Serviços de limpeza urbana; Áreas de proteção } \\
\text { ambiental. }\end{array}$ \\
\hline
\end{tabular}

Inicialmente, para cada um dos indicadores, foram calculados seus respectivos índices para os bairros de Natal, a partir da mediana dos valores obtidos para cada indicador. Assim como a média, a mediana é uma medida de posição, que indica o valor central do conjunto de dados univariados, independente das características de sua distribuição. Isso faz da mediana uma medida mais robusta que a média, isto é, menos sensível à presença de valores discrepantes que, por ventura, possam existir no conjunto analisado, permitindo com que se tenha um valor mais fidedigno e com menos erros de interpretação gerados por 
algum viés dos dados.

Com base nos índices calculados fez-se uso do Microsoft Exce ${ }^{\circledR}$ para estabelecer uma análise hierárquica entre os bairros e regiões e assim, identificar quais bairros e regiões são mais vulneráveis. Em seguida, a partir da sua representação, foi construído o mapa de calor com as correlações lineares existentes entre os bairros de Natal (RN), a fim de que se pudesse identificar as similaridades e diferenças existentes entre as regiões administrativas da cidade.

\section{Representação}

Os índices analisados variam entre 0 e 1 , onde quanto mais próximo de 1 , melhor se apresenta o bairro e/ou a região em relação às questões que envolvem a vulnerabilidade. Sendo assim, os valores de mínimo e máximo correspondem, respectivamente, a 1 (baixa vulnerabilidade ou padrão ideal e 0 (alta vulnerabilidade). Para a representação dos índices referentes a cada indicador definiu-se a representação de cor correspondente ao nível de vulnerabilidade socioambiental urbano.

Quadro 3: Classificação e representação dos índices em níveis de vulnerabilidade socioambiental para cidades brasileiras.

\begin{tabular}{|l|l|l|}
\hline Índice (0 - 1) & Representação de cores & Nível de Vulnerabilidade Socioambiental Urbano \\
\hline $0,0000-0,2500$ & & Muito alto \\
\hline $0,2501-0,5000$ & & Alto \\
\hline $0,5001-0,7500$ & & Baixo \\
\hline $0,7501-1,0000$ & & Muito baixo \\
\hline
\end{tabular}

\section{Análise de Correlação Linear}

A partir do cálculo dos índices de vulnerabilidade para cada bairro, foi utilizado o cálculo do Coeficiente de Correlação Linear de Pearson ( $r$ ) que mede o grau de correlação linear entre duas variáveis quantitativas. É um índice adimensional com valores situados entre -1,0 e 1,0 inclusive, e reflete a intensidade de uma relação linear entre dois conjuntos de dados (BUSSAB et al., 2013).

Este coeficiente, normalmente representado pela letra ' $r$ ' assume apenas valores entre -1 e 1 .

$r=1$ significa uma correlação perfeita positiva entre as duas variáveis.

$r=-1$ significa uma correlação negativa perfeita entre as duas variáveis, ou seja, se uma aumenta, a outra sempre diminui.

$r=0$ significa que as duas variáveis não se correlacionam.

Para este artigo foi estabelecido seguinte parâmetro de análise para interpretação dos dados:

Quadro 4: Medidas de correlação e intepretação

\begin{tabular}{|l|l|}
\hline Valor de $r$ & Interpretação \\
\hline$-0,33 \leq r<0,33$ & Correlação linear fraca \\
\hline$-0,67 \leq r<-0,33$ ou $0,33 \leq r<0,67$ & Correlação linear moderada \\
\hline$-1,00 \leq r<-0,67$ ou $0,67 \leq r \leq 1,00$ & Correlação linear forte \\
\hline
\end{tabular}

A escolha das medidas relacionadas no quadro 04 garante que as três possibilidades de classificação estão associadas a intervalos de valores de $r$ de mesmo tamanho, garantindo, assim, a ausência de viés na análise. Definido o percurso metodológico utilizado para alcance do objetivo deste estudo, o tópico a seguir 
apresenta e analisa os resultados obtidos.

\section{RESULTADOS}

\section{Apresentação e análise dos resultados}

\section{Caracterização da cidade de Natal}

A cidade escolhida para a realização deste estudo foi Natal capital do estado do Rio Grande do Norte, na região Nordeste do Brasil. Segundo o IBGE (2010) a referida cidade possui uma área territorial de 167,264 $\mathrm{km}^{2}$ e sua população é estimada em 885.173 habitantes. Criada já com caráter de cidade, Natal foi fundada em 25 de dezembro de 1599 (IBGE, 2010). Sua urbanização teve seu início por meio da colonização portuguesa e seu aumento populacional ocorreu de forma lenta. No final do século XIX a cidade possuía apenas 16.050 habitantes (IBGE, 2010). O crescimento urbano da cidade aconteceu de forma mais evidente com a deflagração da Segunda Guerra Mundial, uma vez que a posição estratégica da cidade e a utilização da Base Aérea de Parnamirim atraiu considerável fluxo migratório responsável pelo acelerado crescimento demográfico e econômico da cidade.

Segundo Costa (2007), os investimentos habitacionais e as políticas públicas de Estado e de Governo em Natal também foram estabelecidas segregando espacialmente a cidade. Ao passo que as habitações para a população de alta renda eram realizadas na Zona Sul da cidade, as habitações para a população mais pobre eram construídas na Zona Norte da cidade. A região administrativa Norte é composta por 07 bairros (Lagoa Azul, Nossa Senhora da Apresentação, Igapó, Potengi, Pajuçara, Redinha e Salinas) e abriga 360.122 habitantes, segundo estimativa do IBGE (2017), sendo considerada a maior tanto em área territorial, quanto em número de habitantes.

A região administrativa Sul é composta por 07 bairros (Lagoa Nova, Nova Descoberta, Candelária, Capim Macio, Pitimbu, Neópolis, Ponta Negra) e abriga 175.332 habitantes, segundo estimativa do IBGE (2017). A região administrativa Leste é composta pelos primeiros bairros da cidade, e no total, compreende uma área composta por 12 bairros (Santos Reis, Rocas, Ribeira, Praia do Meio, Cidade Alta, Petrópolis, Areia Preta, Alecrim, Barro Vermelho, Lagoa Seca, Tirol, Mãe Luiza) e contam com 114.649 habitantes (IBGE, 2017).

A região administrativa Oeste compreende 10 bairros (Nordeste, Quintas, Bom Pastor, Dix-Sept Rosado, Nossa Senhora de Nazaré, Felipe Camarão, Cidade da Esperança, Guarapes, Cidade Nova, Planalto) e abriga um total de 235.070 habitantes, segundo o IBGE (2017). É importante também destacar as características naturais da cidade: Natal apresenta uma diversidade de ecossistemas, dentre os quais destaca-se os estuários, planícies de mangue, praias, terraços e vales fluviais, campos dunares, restingas e mata atlântica.

\section{Índice de Vulnerabilidade Socioambiental dos bairros de Natal}

O cálculo do índice de vulnerabilidade socioambiental dos bairros de Natal permite identificar quais os bairros e regiões que se apresentam em situação de maior vulnerabilidade, conforme pode ser visualizado 
no Quadro 4. Os dados referentes a cada um dos indicadores foram catalogados a partir da consulta nas bases de dados que disponibilizam informações referentes às cidades brasileiras, dentre as quais o IBGE, Prefeitura Municipal de Natal (RN), Datasus, Anatel, Tribunal Regional Eleitoral, Secretaria do Tesouro Nacional, Ministério das Cidades, Ministério da Cultura. Os índices dos temas foram calculados a partir da mediana dos indicadores por bairro que constituem cada tema. $\mathrm{O}$ mesmo procedimento foi utilizado para o cálculo das dimensões e do índice de vulnerabilidade socioambiental de Natal.

Quadro 5: Índice de vulnerabilidade socioambiental Urbano de Natal - RN.

índice de vulnerabilidade socioambiental de Natal - RN

\begin{tabular}{|c|c|c|c|c|c|c|c|c|}
\hline \multirow[b]{2}{*}{$\begin{array}{l}\text { Região } \\
\text { Administrati } \\
\text { va }\end{array}$} & \multirow[b]{2}{*}{ Bairro } & \multicolumn{4}{|l|}{ Social } & \multicolumn{2}{|l|}{ Ambiental } & \multirow[b]{2}{*}{$\begin{array}{l}\text { Índice de Vulnerabilidade Socioambiental por } \\
\text { bairros }\end{array}$} \\
\hline & & $\begin{array}{l}\text { Índice } \\
\text { do } \\
\text { Tema } \\
\text { Saúde }\end{array}$ & $\begin{array}{l}\text { Índice } \\
\text { do Tema } \\
\text { Educaçã } \\
\text { o e } \\
\text { Cultura }\end{array}$ & $\begin{array}{l}\text { Índice } \\
\text { do } \\
\text { Tema } \\
\text { Trabalh } \\
\text { o e } \\
\text { Renda } \\
\end{array}$ & $\begin{array}{l}\text { Índice } \\
\text { do } \\
\text { Tema } \\
\text { Moradi } \\
\text { a }\end{array}$ & $\begin{array}{l}\text { Índice do } \\
\text { Tema } \\
\text { Infraestrutu } \\
\text { ra Urbana }\end{array}$ & $\begin{array}{l}\text { Índice } \\
\text { do Tema } \\
\text { Meio } \\
\text { Ambient } \\
\text { e }\end{array}$ & \\
\hline \multirow{12}{*}{ Leste } & Alecrim & 0,3374 & 0,3368 & 0,3563 & 0,5355 & 0,4617 & 0,2837 & 0,3468 \\
\hline & Areia Preta & 0,0648 & 0,2609 & 0,9421 & 0,8746 & 0,1184 & 0,3496 & 0,3052 \\
\hline & $\begin{array}{l}\text { Barro } \\
\text { Vermelho }\end{array}$ & 0,1710 & 0,1878 & 0,6944 & 0,9482 & 0,1721 & 0,2952 & 0,2415 \\
\hline & Cidade Alta & 0,0431 & 0,4922 & 0,5225 & 0,6111 & 0,6290 & 0,2217 & 0,5073 \\
\hline & Lagoa Seca & 0,8548 & 0,1769 & 0,6944 & 0,8863 & 0,2807 & 0,1883 & 0,4876 \\
\hline & Mãe Luiza & 0,6230 & 0,2829 & 0,5621 & 0,4802 & 0,0788 & 0,8359 & 0,5211 \\
\hline & Petrópolis & 0,8217 & 0,4038 & 0,8443 & 0,7348 & 0,3196 & 0,0577 & 0,5693 \\
\hline & $\begin{array}{l}\text { Praia do } \\
\text { Meio }\end{array}$ & 0,0603 & 0,2517 & 0,5009 & 0,6667 & 0,2787 & 0,3107 & 0,2947 \\
\hline & Ribeira & 0,4743 & 0,3723 & 0,4624 & 0,4394 & 0,4123 & 0,5155 & 0,4509 \\
\hline & Rocas & 0,4141 & 0,2278 & 0,6183 & 0,8484 & 0,4024 & 0,2691 & 0,4082 \\
\hline & Santos Reis & 0,4737 & 0,1946 & 0,4369 & 0,5143 & 0,4914 & 0,8795 & 0,4825 \\
\hline & Tirol & 0,9857 & 0,4674 & 1,0000 & 0,9060 & 0,4214 & 0,5189 & 0,7125 \\
\hline \multirow{7}{*}{ Norte } & Igapó & 0,3056 & 0,2688 & 0,3895 & 0,7657 & 0,1741 & 0,9730 & 0,3475 \\
\hline & Lagoa Azul & 0,0855 & 0,4537 & 0,2279 & 0,6667 & 0,4019 & 0,9116 & 0,4278 \\
\hline & $\begin{array}{l}\text { N. Sra. da } \\
\text { Apresentaç } \\
\text { ão }\end{array}$ & 0,2439 & 0,3749 & 0,2737 & 0,5385 & 0,1909 & 0,8076 & 0,3243 \\
\hline & Pajuçara & 0,1352 & 0,3377 & 0,2279 & 0,7666 & 0,2796 & 0,9542 & 0,3087 \\
\hline & Potengi & 0,5635 & 0,6417 & 0,5827 & 0,8619 & 0,6044 & 0,9692 & 0,6231 \\
\hline & Redinha & 0,1554 & 0,1510 & 0,1744 & 0,3846 & 0,2444 & 0,9310 & 0,2094 \\
\hline & Salinas & 0,0000 & 0,0000 & 0,0000 & 0,2995 & 0,0000 & 0,7452 & 0,0000 \\
\hline \multirow{10}{*}{ Oeste } & Bom Pastor & 0,1651 & 0,1348 & 0,3302 & 0,4041 & 0,4092 & 0,8584 & 0,3671 \\
\hline & Cidade Nova & 0,0353 & 0,0744 & 0,2395 & 0,2131 & 0,2284 & 0,9025 & 0,2207 \\
\hline & $\begin{array}{l}\text { Cidade da } \\
\text { Esperança }\end{array}$ & 0,2500 & 0,2503 & 0,7705 & 0,9423 & 0,2943 & 0,7701 & 0,5322 \\
\hline & $\begin{array}{l}\text { Dix-Sept } \\
\text { Rosado } \\
\end{array}$ & 0,1389 & 0,2950 & 0,4989 & 0,6830 & 0,0486 & 0,7600 & 0,3970 \\
\hline & $\begin{array}{l}\text { Felipe } \\
\text { Camarão }\end{array}$ & 0,4589 & 0,4180 & 0,4644 & 0,6106 & 0,3807 & 0,9225 & 0,4617 \\
\hline & Guarapes & 0,1583 & 0,1167 & 0,2014 & 0,3077 & 0,2511 & 0,9328 & 0,2262 \\
\hline & Nordeste & 0,0556 & 0,1843 & 0,3648 & 0,6667 & 0,4240 & 0,8155 & 0,3944 \\
\hline & $\begin{array}{l}\text { Nossa } \\
\text { Senhora de } \\
\text { Nazaré }\end{array}$ & 0,2588 & 0,2815 & 0,6712 & 0,8402 & 0,1716 & 0,8011 & 0,4763 \\
\hline & Planalto & 0,2684 & 0,1702 & 0,3044 & 0,5581 & 0,1076 & 0,9001 & 0,2864 \\
\hline & Quintas & 0,4400 & 0,3052 & 0,3473 & 0,8333 & 0,3333 & 0,9351 & 0,3937 \\
\hline \multirow{7}{*}{ Sul } & Candelária & 0,3379 & 0,1336 & 0,9226 & 0,5342 & 0,4222 & 0,7252 & 0,4782 \\
\hline & $\begin{array}{l}\text { Capim } \\
\text { Macio }\end{array}$ & 0,1774 & 0,2651 & 0,9108 & 0,6923 & 0,4214 & 0,6670 & 0,5442 \\
\hline & Lagoa Nova & 0,1736 & 0,6657 & 0,7750 & 0,7594 & 0,5740 & 0,2231 & 0,6199 \\
\hline & Neópolis & 0,3718 & 0,3253 & 0,8372 & 0,9022 & 0,6426 & 0,7115 & 0,6770 \\
\hline & $\begin{array}{l}\text { Nova } \\
\text { Descoberta }\end{array}$ & 0,3472 & 0,2794 & 0,6394 & 0,7588 & 0,2916 & 0,8018 & 0,4933 \\
\hline & Pitimbu & 0,3335 & 0,3361 & 0,7408 & 0,9767 & 0,3659 & 0,7100 & 0,5379 \\
\hline & Ponta Negra & 0,1692 & 0,3433 & 0,5583 & 0,7798 & 0,4796 & 0,6140 & 0,5190 \\
\hline
\end{tabular}

Dos 36 bairros, 25 se encontram em situação que os classificam com um nível 'Alto' ou 'Muito Alto' 
para a vulnerabilidade socioambiental, o que explicita que a cidade apresenta maiores fragilidades especialmente nos temas relacionados as questões sociais, principalmente de moradia, de educação e cultura, de emprego e renda e na disparidade existente frente as questões de infraestrutura urbana.

Uma observação que merece destaque é que nenhum dos 36 bairros de Natal obteve o nível 'muito baixo' de vulnerabilidade socioambiental, evidenciando que apesar de alguns bairros de destacarem com alguns aspectos considerados bons, de um modo geral, a cidade precisa criar mecanismos eficazes para que o seu desenvolvimento aconteça de forma harmônica e equitativa, equilibrando os índices e possibilitando uma cidade menos vulnerável, com melhores condições de vida e maior justiça social.

Com base no cálculo dos índices de vulnerabilidade socioambiental encontrado para cada bairro da cidade de Natal (RN) e, visando aprofundar a análise, foi possível estabelecer a análise de correlação linear entre eles, possibilitando a identificação das similaridades existentes entre as regiões. Para tanto, foram elaborados os mapas de calor das correlações dos índices comparativos entre as regiões, calculados por meio do Coeficiente de Correlação Linear de Pearson. Com base nos dados explicitados na Figura 1, procede-se para a análise comparativa entre as regiões, evidenciando, quando necessário, os bairros que se destacaram com maior similaridade entre si.

Região Norte e Região Leste: a análise de correlação realizada entre estas duas regiões estão representadas na figura 1.

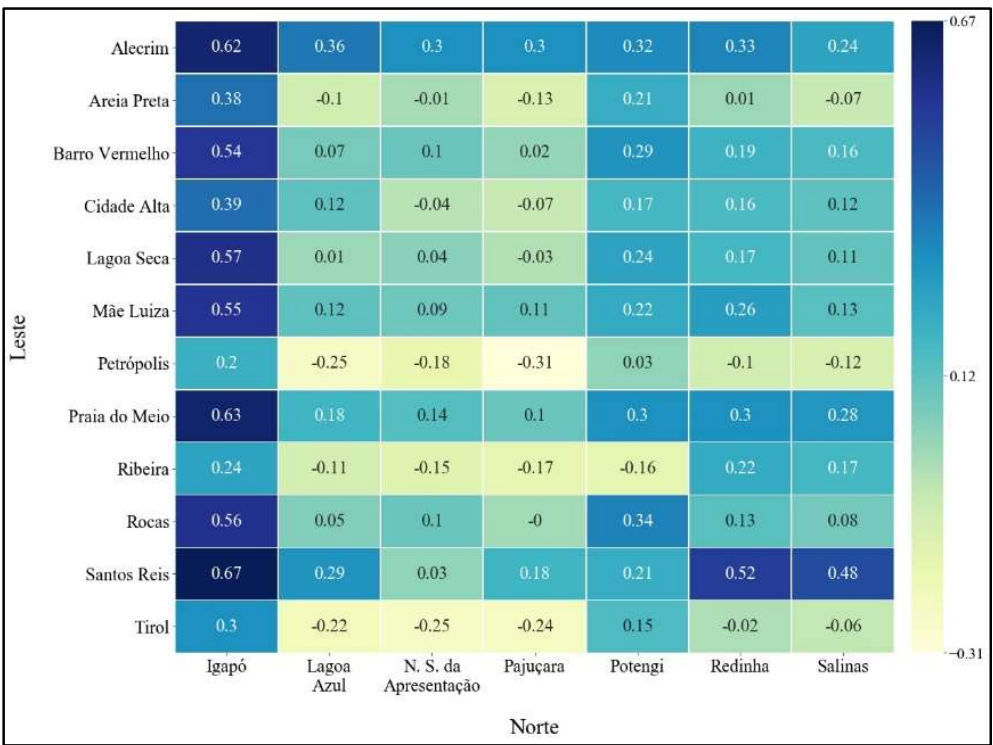

Figura 1: Mapa de calor das correlações lineares entre as regiões Norte e Leste

Ao se observar as correlações existentes entre estas duas regiões, é possível ver que das 84 medidas de correlação, 66 apresentam-se com correlação linear fraca predominante, representando $78 \%$ das medidas. 17 medidas apresentaram correlação linear moderada, representando 20,23\%, e apenas 1 medida é considerada correlação linear forte.

Essas duas regiões são bem divergentes sob o ponto de vista econômico da cidade. A região Norte caracteriza-se por ser uma das regiões mais pobres da cidade, enquanto a região Leste se insere como uma das mais ricas. Além disso, a região Norte apresentou nível classificado como 'Muito Alto' para a 
vulnerabilidade socioambiental nos temas Saúde, Trabalho e Renda e Infraestrutura Urbana e nível 'Alto' para Educação e Cultura. Enquanto a região Leste apresentou nível alto apenas para o tema Educação e Cultura e os demais temas se enquadram no nível 'Baixo' ou 'Muito baixo'. Esses dados revelam a disparidade existente entre os bairros das duas regiões, endossando inclusive, que o fator econômico da região Leste permite com que haja maior disponibilidade a serviços básicos e de acesso a estrutura da cidade e que são escassos na região Norte.

É importante destacar que na região Norte o bairro Igapó apresentou as medidas de correlação mais altas com os bairros da região Leste, muito embora sejam classificadas como correlação linear moderada. Essa informação evidencia similaridade deste bairro com a Região Leste, sobretudo com os bairros Santos Reis (correlação linear forte), Praia do Meio, Alecrim, Rocas e Lagoa Seca (correlação linear moderada) dado que os índices dos temas do Igapó se apresentam melhores do que os demais bairros da região em que está localizado, colocando-o em situação semelhante dos bairros da região Leste. O bairro de Igapó é um ponto de passagem obrigatória para as pessoas que moram na região Norte da cidade, bem como em outros municípios que fazem divisa com Natal, convergindo, dessa forma, fácil acesso para ônibus intermunicipal e intramunicipal. Essa característica do bairro, faz com que haja uma série de investimentos de empreendimentos comerciais, permitindo com que haja maior visibilidade para o bairro.

Região Norte e Região Sul: a análise de correlação linear realizada entre estas duas regiões estão representadas na figura 2 .

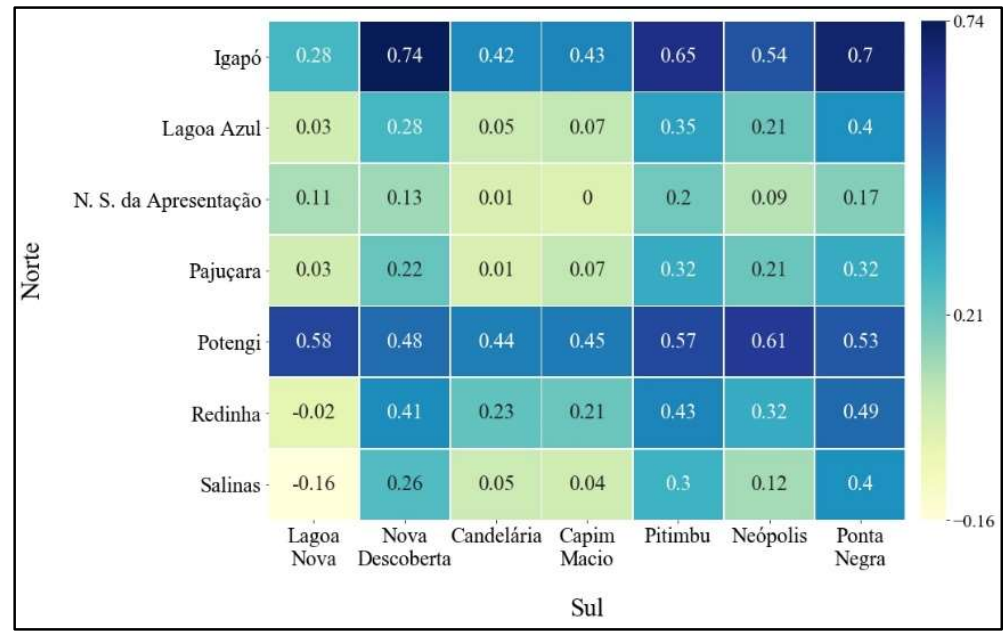

Figura 2: Mapa de calor das correlações lineares entre as regiões Norte e Sul

Das 49 medidas de correlação, 26 medidas se classificam como correlação linear fraca, representando 53,06\%, 20 como correlação linear mediana, representando 40,81\% e 02 como correlação linear forte. 94\% das medidas estão entre fraca e mediana, denotando divergência entre as regiões. A região Norte, como já explicitado anteriormente, é pobre e apresentou nível classificado como 'Muito Alto' para a vulnerabilidade socioambiental nos temas Saúde, Trabalho e Renda e Infraestrutura Urbana e nível 'Alto' para Educação e Cultura.

A região Sul é a região turística da cidade e, por esse motivo, atrai o olhar dos investimentos da cidade e concentra pessoas com o maior poder aquisitivo da cidade. A região não apresentou nenhum tema 
classificado como 'Muito alto' para a vulnerabilidade socioambiental, classificando-se como 'Alto' para os temas Saúde e Educação e Cultura e Infraestrutura urbana. Por ser uma região essencialmente turística, a região concentra um quantitativo maior de uma estrutura voltada para atendimento ao turista, como por exemplo: hotéis, pousadas, bares, restaurantes e lojas de artesanatos. Os estabelecimentos de saúde, como clínicas e hospitais, bem como as escolas estão localizadas em outras regiões da cidade. Com relação à Infraestrutura Urbana apresentou-se com índice alto em decorrência da baixa cobertura da rede de esgotos, além das características naturais da região: presença dos campos dunares e alto potencial de infiltração no solo. No entanto, é importante destacar a necessidade de melhoria efetiva nos aspectos estruturais da região que possa proporcionar melhor condições de vida para os seus moradores.

Os bairros que apresentaram uma medida de correlação linear forte foram Ponta Negra e Nova Descoberta (região Sul) com Igapó (região Norte), evidenciando mais uma vez o diferencial do bairro Igapó frente a região Norte da cidade, dada a sua estrutura e sua localização privilegiada que permite maiores investimentos particulares. Ademais, foram nos temas Saúde, Educação e Cultura e Moradia que houve maior convergência entres os bairros. Nos dois primeiros temas os três bairros se classificaram com nível 'Alto' para a vulnerabilidade, enquanto que no tema Moradia os três bairros se classificaram com um nível 'Muito baixo' para a vulnerabilidade socioambiental.

Região Leste e Região Oeste: a análise de correlação linear realizada entre estas duas regiões estão representadas na figura 3 .

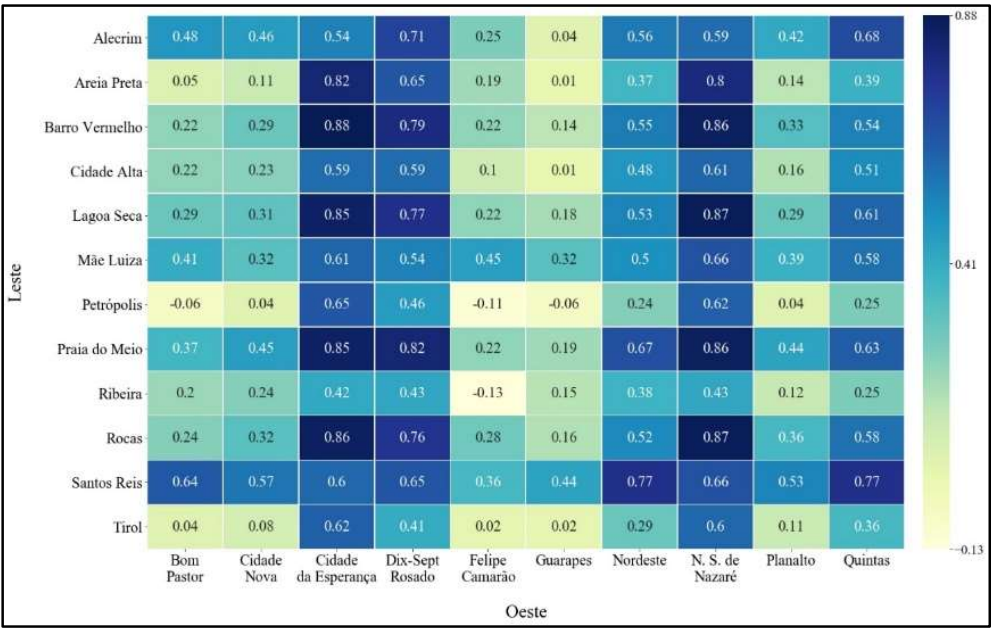

Figura 3: Mapa de calor das correlações lineares entre as regiões Leste e Oeste

Das 120 medidas de correlação obtidas dos 22 bairros, 43 medidas classificam-se como correlação linear fraca, representando 35,8\% das medidas, 58 como correlação linear mediana, representando $48,4 \%$ das medidas e 19 como correlação linear forte, representando 15,8\% das medidas. Como já foi destacado a região Leste é a região onde reside a população com maior poder aquisitivo da cidade, diferentemente da região Oeste que é uma das regiões mais pobres da cidade. A região Leste apresentou nível 'Alto' apenas para o tema Educação e Cultura e os demais temas se enquadram no nível 'Baixo' ou 'Muito baixo'. Já a região Oeste apresenta nível 'Muito alto' de vulnerabilidade socioambiental para os temas Saúde, Educação e cultura e nível 'Alto' para Trabalho e renda e Infraestrutura urbana. É importante destacar que esta região 
Oeste compõe três ZPA: parte da ZPA-1 e ZPA-4 que abrigam os campos dunares, e a ZPA-8 que compreende o ecossistema manguezal e estuário do Rio Potengi/Jundiaí, favorecendo, em função da ocupação irregular riscos de deslizamentos e enchentes.

O bairro Nossa Senhora de Nazaré (região Oeste) foi o que apresentou maior similaridade com os bairros da região Leste, apresentando 7 medidas de um total de 12, classificada como uma medida de correlação linear forte. Esse dado revela a similaridade desse bairro sobretudo com os bairros Areia Preta, Barro Vermelho, Mãe Luiza, Praia do Meio, Rocas e Santos Reis. Alguns desses bairros são considerados pobres da região Leste e demandam um olhar mais atento para que haja um melhor planejamento e maior direcionamento de recursos para melhoria desses bairros.

Região Sul e Região Oeste: a análise de correlação linear realizada entre estas duas regiões estão representadas na figura 4 .

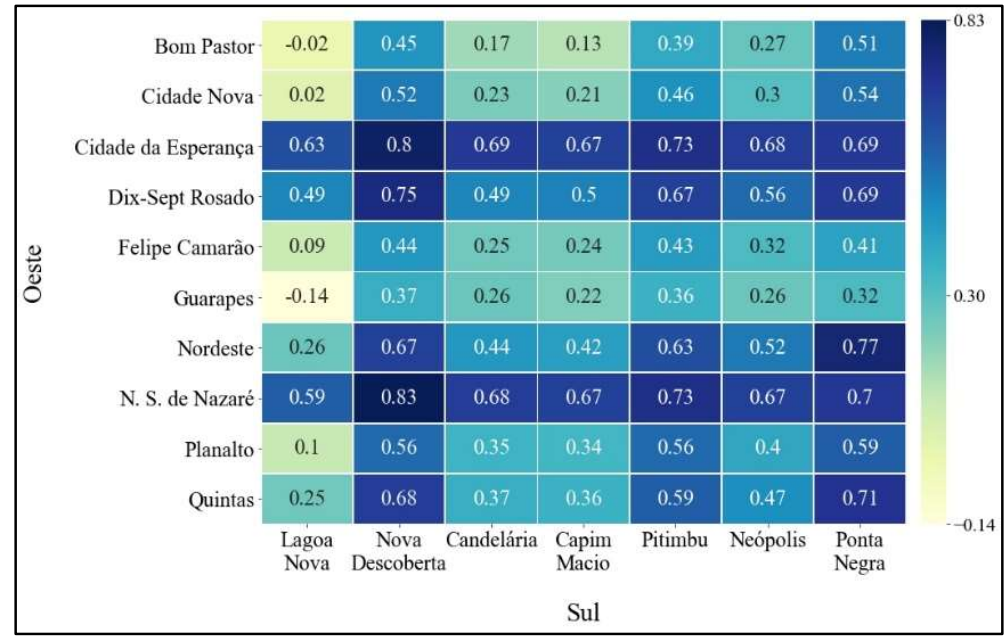

Figura 4: Mapa de calor das correlações lineares entre as regiões Sul e Oeste

Das 70 medidas de correlação existentes para estas regiões, 18 medidas apresentaram-se com correlação linear fraca, 18 com medida de correlação forte, representando $25,7 \%$ das medidas cada e 34 com medida de correlação moderada, representando 48,6 \%. A disparidade existente entre as regiões é evidente. A região Sul é turística e apresenta todo uma estrutura voltada para tal atividade, além de ser a região que as pessoas detêm o maior poder aquisitivo da cidade. A região Oeste é carente de infraestrutura, sobretudo no acesso às questões básicas para a população. Como já evidenciado a região Oeste apresenta nível 'Muito alto' de vulnerabilidade socioambiental para os temas Saúde, Educação e cultura e nível 'Alto' para Trabalho e renda e Infraestrutura urbana. Já a região Sul não apresentou nenhum tema classificado como 'Muito alto' para a vulnerabilidade socioambiental, classificando-se como 'Alto' para os temas Saúde e Educação e Cultura e Infraestrutura urbana.

O bairro Cidade da Esperança (região Oeste) foi o bairro que apresentou mais medidas de correlação linear forte com os bairros da região Sul. Das 7 medidas de correlação, 6 são correlação linear forte e 1 correlação linear moderada. Esse dado reflete a similaridade de Cidade da Esperança com os bairros Candelária, Capim Macio, Neópolis, Nova Descoberta, Pitimbu e Ponta Negra. Apesar de localizado em uma região mais pobre, este bairro é um dos mais tradicionais da cidade e onde foi construído inicialmente o 
primeiro conjunto habitacional também denominado Cidade da Esperança, e fazia parte de um Plano de Habitação Popular, concebido para reverter o déficit habitacional potiguar. Dada as suas características de planejamento e desenvolvimento, é um bairro que detém muitos comércios, supermercados, feira livre, rodoviária com linhas intermunicipal e interestadual, acesso ao transporte público, facilitando o acesso dos moradores para todas as outras regiões da cidade. São essas características que posicionam o bairro em uma situação mais similar com os bairros da região Sul.

Região Norte e Região Oeste: a análise de correlação linear realizada entre estas duas regiões estão representadas na figura 5 .

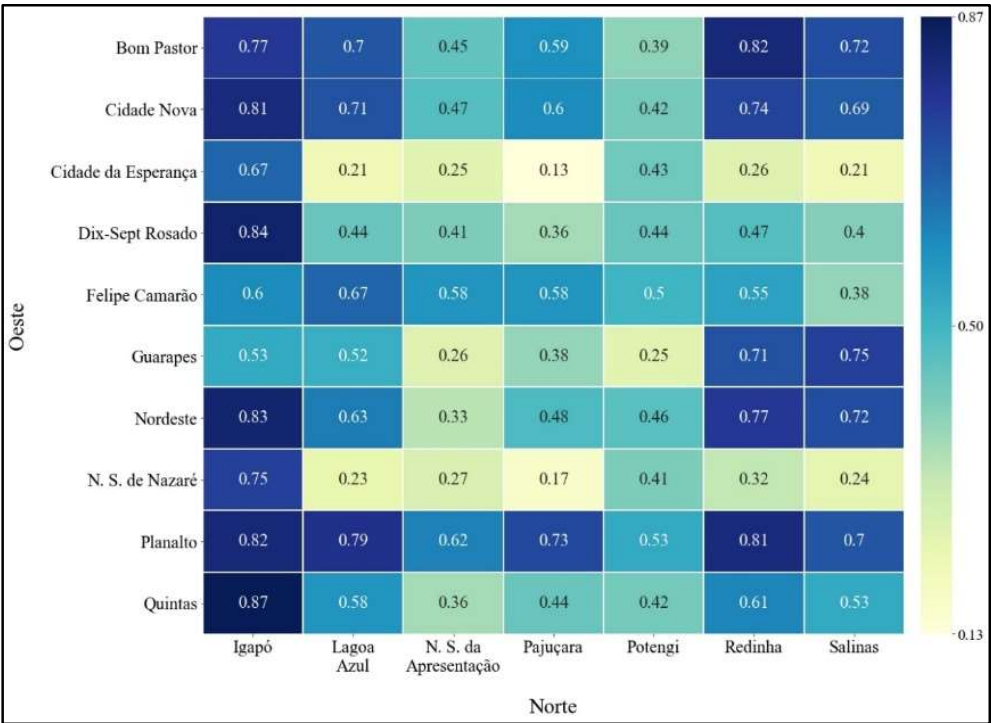

Figura 5: Mapa de calor das correlações lineares entre as regiões Norte e Oeste

Das 70 medidas de correlação representadas na figura 5, 10 são medidas de correlação linear fraca, representando 14,29\%, 38 são medidas de correlação moderada, representando 54,28\% e 22 são medidas de correlação forte, representando $31,43 \%$.

Essas regiões são as que concentram o locus de pobreza da cidade. Apesar de todas as regiões administrativas tenham comunidades caracterizadas pela pobreza, pela falta de estrutura que garantam as condições mínimas de moradia e qualidade de vida, são nessas duas regiões que se apresentam os índices de vulnerabilidade socioambiental classificados como 'Muito alto'.

A região Norte, como já explicitado anteriormente, é um bairro pobre e apresentou nível classificado como 'Muito Alto' para a vulnerabilidade socioambiental nos temas Saúde, Trabalho e Renda e Infraestrutura Urbana e nível ‘Alto' para Educação e Cultura. A região Oeste apresentou nível 'Muito alto' de vulnerabilidade socioambiental para os temas Saúde, Educação e cultura e nível 'Alto' para Trabalho e renda e Infraestrutura urbana.

O bairro de Igapó (região Norte) foi o que apresentou mais medidas de correlação linear forte com os bairros da região Oeste. Das 10 medidas de correlação, 7 são correlação linear forte e 3 correlações linear moderada. Esse dado reflete que apesar de ser um bairro bem localizado e estruturado, como já evidenciado, o bairro Igapó reflete as dificuldades de estar inserido em uma região pobre da cidade, no qual enfrenta dificuldades evidenciados pelos temas Saúde, Educação e cultura e Trabalho e Renda. 
Região Leste e Região Sul: a análise de correlação linear realizada entre estas duas regiões estão representadas na figura 6.

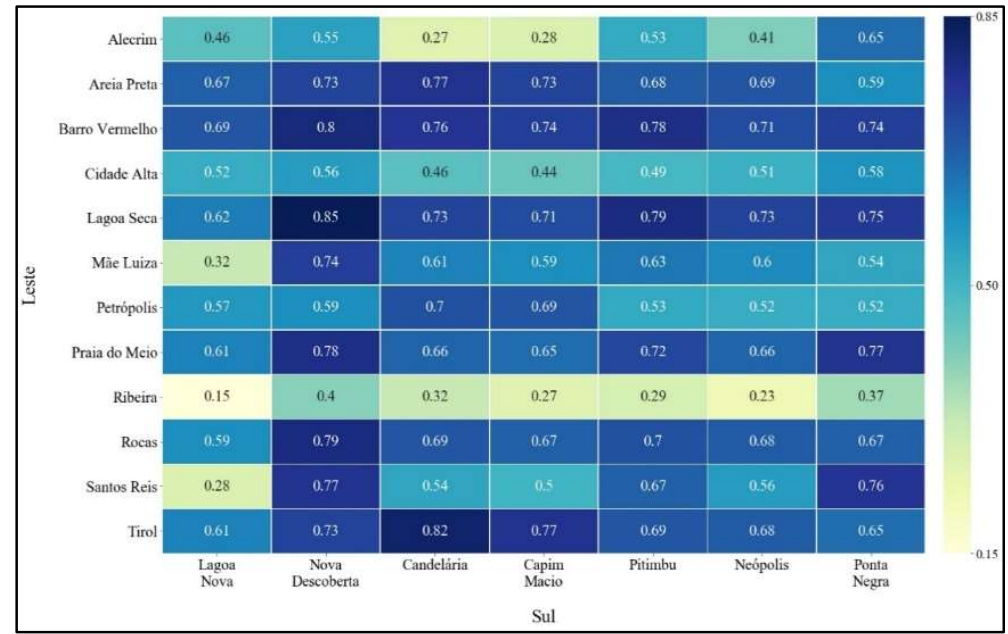

Figura 6: Mapa de calor das correlações lineares entre as regiões Leste e Sul

Das 84 medidas de correlação linear para estas regiões, 9 são medidas de correlação linear fraca, representando 10,71\%, 39 são de correlação linear moderada 46,43\% e 36 de medidas de correlação linear forte, representando $42,86 \%$. Apesar de apresentar a correlação linear mediana como preponderante, a correlação linear forte obteve um percentual significativo.

As duas regiões se assemelham por serem as regiões mais ricas da cidade e concentrarem os maiores rendimentos nominal médio mensal, com 3,31 e 3,09 salários mínimos, respectivamente. A região Leste apresentou nível 'Alto' apenas para o tema Educação e Cultura e os demais temas se enquadram no nível 'Baixo' ou 'Muito baixo'. A região Sul não apresentou nenhum tema classificado como 'Muito alto' para a vulnerabilidade socioambiental, classificando-se como 'Alto' para os temas Saúde e Educação e Cultura e Infraestrutura urbana.

O bairro Nova Descoberta (região Sul) foi o que mais apresentou similaridade com a região Leste, sobretudo com os bairros Areia Preta, Barro Vermelho, Lagoa Seca, Mãe Luiza, Praia do Meio, Rocas, Santos Reis e Tirol. É considerado um bairro com uma infraestrutura adequada para moradia dada a proximidade à UFRN (Universidade Federal do Rio Grande do Norte), acesso a unidades básicas de saúde, escolas particulares e públicas, restaurantes e clínicas. No entanto, há dificuldades quanto ao acesso à transporte público.

Uma observação importante a ser feita na análise das regiões que se enquadraram na classificação de correlação linear moderada é que, apesar das diferenças absolutas entre os índices dos bairros das regiões analisadas, a maior parte das correlações lineares entre os bairros dessas regiões apresentaram correlação linear mediana. Esse resultado explicita um certo grau de similaridade da distribuição dos valores dos índices dos bairros de cada região, não indicando, porém, que as regiões em si são similares ou que existe alguma relação direta ou causal entre eles.

Com base nos resultados apresentados foi possível verificar que não houve, entre as regiões, correlação linear forte, apesar de haver, do modo específico, correlação forte entra alguns bairros. A região 
Norte foi a região que apresentou um nível de vulnerabilidade classificado como 'Alto'. Essa também é a região mais pobre de Natal e, por conseguinte, a que apresenta os problemas mais latentes nas questões referentes aos temas analisados, sobretudo, Saúde, Trabalho e renda, Infraestrutura Urbana, Educação e cultura. Tal fato o coloca em um nível de correlação linear fraca e de disparidade frente as regiões mais abastadas da cidade: região Leste e região Sul.

\section{CONCLUSÕES}

Analisar uma cidade traçando um comparativo entre seus bairros e estabelecendo uma hierarquia para identificar quais os mais ou menos vulneráveis, configura um importante avanço nos estudos acerca da vulnerabilidade socioambiental, pois é possível retratar qual região e quais bairros necessitam de maiores investimentos públicos para sanar as problemáticas sociais e ambientais que os envolvem. Desse modo, identificar os bairros mais frágeis da cidade permite que se estabeleça um grau de prioridade no direcionamento de políticas públicas para a mitigação destes problemas e que visem o bem-estar da sociedade e o direcionamento planejado de recursos.

Com base nos resultados alcançados foi possível identificar que as regiões Norte e Oeste são as mais vulneráveis e são as que demandam maior necessidade de planejamento que visem a implementação de ações para reverter o cenário de vulnerabilidade socioambiental que apresentaram. As questões representadas pelos temas Saúde, Educação e cultura, Trabalho e renda e Infraestrutura urbana, foram as mais latentes, constituindo aspectos sociais fundamentais para que qualquer cidadão possa ter garantido sua sobrevivência e sua dignidade.

As correlações lineares apresentadas permitiram a identificação das similaridades e diferenças entre bairros e, sobretudo entre as regiões administrativas, delineando análises mais aprofundadas e permitindo descobrir minúcias da cidade não perceptíveis em uma primeira análise. De forma equânime, as questões relativas às problemáticas sociais foram as que se apresentaram mais negativamente, demandando maior atenção por parte da gestão pública e, por conseguinte, urgência no seu equacionamento.

Desse modo, verifica-se a importância de analisar a cidade com um olhar mais direcionado para cada região e para cada bairro, pois cada um apresentaram especificidades que os colocam em divergência em vários aspectos, mesmo quando exibem as mesmas problemáticas. Estas observações ficam evidentes quando se compreende o surgimento histórico de cada região, de cada bairro e seus respectivos processos de ocupação espacial, compreendendo também, as suas necessidades mais prementes. Nesse sentido, tornase urgente que se pense a cidade de modo que o seu crescimento aconteça de forma equitativa, que os recursos possam ser direcionados levando em conta as necessidades de cada bairro e de cada região e que todos possam usufruir de forma igualitária da cidade em que moram.

\section{REFERÊNCIAS}

ALVES, H. P. F.. Vulnerabilidade socioambiental na metrópole paulistana: uma análise sociodemográfica das situações de sobreposição espacial de problemas e riscos sociais e ambientais. Revista Brasileira de Estudos de População, v.23, n.1, p.43-59, 2006.

DOI: http://dx.doi.org/10.1590/S0102-30982006000100004 
ARAÚJO, M. C. C.; CÂNDIDO, G. A.. Qualidade de vida e sustentabilidade urbana. Revista HOLOS, v.30, n.1, p.3-17, 2014. DOI: https://doi.org/10.15628/holos.2014.1720

BRAGA, T. M.. Sustentabilidade e condições de vida em áreas urbanas: medidas e determinantes em duas regiões metropolitanas brasileiras. Revista Eure, v.32, n.96, p.47-71, 2006.

BRAGA, T. M.; FREITAS, A. G.; DUARTE, G. S.. Índice de Sustentabilidade Urbana. In: ENCONTRO DA ASSOCIAÇÃO NACIONAL DE PÓS-GRADUAÇÃO E PESQUISA EM AMBIENTE E SOCIEDADE. Anais. São Paulo, 2002.

COSTA, A. A.. A verticalização de Natal: elemento de impactos socioambientais sobre o seu desenvolvimento urbano. In: NUNES, E.. Dinâmica e gestão do território potiguar. Natal: EDUFRN, 2007. p.267-283.

FIGUEIREDO, A. S.. Índice de qualidade de vida urbana de Campo Grande - MS. Campo Grande: PLANURB, 2008.

FLORISSI, E.. Desenvolvimento Urbano Sustentável: um estudo sobre sistemas de indicadores de sustentabilidade urbana. Dissertação (Mestrado em Desenvolvimento Urbano) - Universidade Federal de Pernambuco, Recife, 2009

GEHL, J.. Cidades para pessoas. São Paulo: Perspectiva, 2015.

GOMES, L. M. S.; GOMES, A. O.. Desenvolvimento e Análise de um Índice de Qualidade de Vida Urbana. In: CONGRESSO BRASILEIRO DE GESTÃO AMBIENTAL, 8. Anais. Campo Grande, 2017.

HERCULANO, S. A.. A qualidade de vida e seus indicadores. Ambiente e Sociedade, v.1, n.2, 2000.

IBGE. Instituto Brasileiro de Geografia e Estatística. Censo Demográfico. Rio de Janeiro: IBGE, 2010.

JACOBS, J.. Morte e vida de grandes cidades. 3 ed. São Paulo: WMF Martins, 2011.

KOWARICK, L.. Escritos Urbanos. São Paulo: 34, 2000.

KOWARICK, L.. Viver em risco: Sobre a vulnerabilidade socioeconômica e civil. São Paulo: 34, 2009.

MACHADO, L.. Índice de Mobilidade Sustentável para avaliar a qualidade de vida urbana: Estudo de caso: Região Metropolitana de Porto Alegre - RMPA. Dissertação (Mestrado em Planejamento Urbano e Regional) Universidade Federal do Rio Grande do Sul, Porto Alegre, 2010.

MAIOR, M. M. S.. Vulnerabilidade socioambiental e expansão urbana: uma proposta metodológica para análise da cidade de João Pessoa-PB. Tese (Doutorado em Recursos Naturais) - Universidade Federal de Campina Grande, Campina Grande, 2014.

MARICATO, E.. O impasse da política urbana no Brasil. 3 ed. Petrópolis: Vozes, 2014.
MARTINS, M. F.; CÂNDIDO, G. A.. Modelo de avaliação do nível de sustentabilidade urbana: proposta para as cidades brasileiras. Revista Brasileira de Gestão Urbana, v.7, n.3, p.397-410, 2015.

MORATO, R. G.. Análise Espacial e Desigualdade Ambiental no Município de São Paulo. Tese (Doutorado em Geografia Humana) - Universidade de São Paulo, São Paulo, 2008.

NAHAS, M. I. P.. Bases teóricas, metodologia de elaboração e aplicabilidade de indicadores intra-urbanos na gestão municipal da qualidade de vida urbana em grandes cidades: o caso de Belo Horizonte. Tese (Doutorado em Ecologia e Recursos Naturais) - Universidade Federal de São Carlos, São Carlos, 2002.

NUNES, E.. O meio ambiente da grande Natal. Natal: Imagens Gráficas, 2000.

PEREIRA, F. S.; VIEIRA, I. C. G.. Expansão urbana da Região Metropolitana de Belém sob a ótica de um sistema de índices de sustentabilidade. Revista Ambiente e Água, Taubaté, v.11, n.3, 2016.

PESSOA, Z. S. A.. Metrópole periférica: identidade e vulnerabilidade socioambiental na Região Metropolitana de Natal-RN/Brasil. Tese (Doutorado em Ciências Humanas) Universidade Estadual de Campinas, São Paulo, 2012.

RIBEIRO, R. J. C.. Índice Composto de Qualidade de Vida Urbana: Aspectos de Configuração Espacial, Socioeconômicos e Ambientais Urbanos. Tese (Doutorado em Arquitetura e Urbanismo) - Universidade de Brasília, Brasília, 2008.

ROGERS, R.. Cidades para um pequeno planeta. São Paulo: Gustavo Gili, 2015.

ROGGERO, M. A.. Um ensaio metodológico sobre a qualidade de vida no distrito de cachoeirinha, zona norte da cidade de São Paulo/SP. Dissertação (Mestrado em Geografia Física) - Universidade de São Paulo, São Paulo, 2009.

ROGGERO, M. A.. Qualidade de vida urbana nas bordas da metrópole: centralidades e periferias. Tese (Doutorado em Geografia Física) - Universidade de São Paulo, São Paulo, 2015.

ROLNIK, R.. Guerra dos Lugares: a colonização da terra e da moradia na era das finanças. São Paulo: Boitempo, 2015.

ROSSETTO, A. M.. Proposta de um Sistema integrado de Gestão do Ambiente Urbano (SIGAU) para o desenvolvimento sustentável de cidades. Tese (Doutorado em Engenharia de Produção) - Universidade Federal de Santa Catarina, Florianópolis, 2003.

SOUZA, J.. Ralé brasileira: quem é e como vive. Belo Horizonte: UFMG, 2009.

SPOSATI, A.. Mapa da exclusão/inclusão social da cidade de São Paulo - 2000. Dinâmica social dos anos 90. São Paulo: Prefeitura de São Paulo, 2000.

VAN BELLEN, H. M.. Indicadores de sustentabilidade: uma análise comparativa. Rio de Janeiro: FGV, 2005. 
VEIGA, A. J. P.. Sustentabilidade urbana, avaliação e

Conquista/BA. Tese (Doutorado em Arquitetura) -

indicadores: um estudo de caso sobre Vitória da

A CBPC - Companhia Brasileira de Produção Científica (CNPJ: 11.221.422/0001-03) detém os direitos materiais desta publicação. Os direitos referem-se à publicação do trabalho em qualquer parte do mundo, incluindo os direitos às renovações, expansões e disseminações da contribuição, bem como outros direitos subsidiários. Todos os trabalhos publicados eletronicamente poderão posteriormente ser publicados em coletâneas impressas sob coordenação da Sustenere Publishing, da Companhia Brasileira de Produção Científica e seus parceiros autorizados. Os (as) autores (as) preservam os direitos autorais, mas não têm permissão para a publicação da contribuição em outro meio, impresso ou digital, em português ou em tradução. 